\title{
Flood Control Lake Toke: Model Development and Model Fitting
}

\author{
Kvam K., Furenes B.*, Hasaas A.*, Gjerseth A., Skeie N.-O., Lie B. \\ University College of Southeast Norway, Porsgrunn, Norway \\ *Skagerak Kraft, Porsgrunn, Norway \\ bernt.lie@usn.no
}

\begin{abstract}
In 2013, Skagerak Kraft AS started a project to automate control of the floodgates in cooperation with the University College of Southeast Norway, Porsgrunn (USN). A prototype of a system was installed in June 2014 using an MPC control algorithm due to the hard and soft concession constraints. However, the model of the system was found to give a poor description of severe floods during a major flood in September 2015.

This article details some adjustments done to the original model of the system. The paper also describes the introduction of a database to handle information for the system, and some uses of such a database.

The updated model shows improvement in floodhandling but other parts of the system model need to be reviewed. The database was successfully integrated in testing, it is to be added to the live server at a later stage.
\end{abstract}

Keywords: flood management, hydropower plant, MATLAB, MPC, SQL database, simulation.

\section{Introduction}

\subsection{Background}

The Dalsfos hydro power plant is located at the outlet of Lake Toke in Telemark, Norway. The waterways leading to Lake Toke, the rivers and lakes downstream of it and down to the ocean are known as the Kragerø waterway. Dalsfos is the first of five hydro power plants downstream of Lake Toke. Dalsfos consists of a dam with intakes to three turbines, two floodgates, and the power station itself just below the dam. The dam at Lake Toke creates a magazine for Dalsfos and the other four hydro power plants downstream, making the four downstream plants in effect run-of-river plants that are dependent on flow from Dalsfos. The turbines are Francis turbines with a combined production capacity of just under $6 \mathrm{MW}$ at a flow rate of $36 \mathrm{~m}^{3} / \mathrm{s}$ through the turbines. The two floodgates are controlled individually from a control room on the dam. The gates have a capacity of $450 \mathrm{~m}^{3} / \mathrm{s}$ each.

Operating hydro power plants come with concession requirements from the Norwegian Water Resources and Energy Directorate (NVE). These concessions dictate the maximum and minimum water levels of Lake Toke, the minimum water flow downstream and the maximum change of water flow.

\subsection{Problem description}

The floodgates at Dalsfos are used to regulate the water level in Lake Toke during a flood. If the regulation is done successfully, it is possible to avoid property damage and risk of injury for people near Lake Toke and the Kragerø waterways. During a flood, water levels rise rapidly and if the floodgates are suddenly opened, the water will do extensive damage to the village downstream of the dam and the roads along the river. Any people close to, or on, the river at the time might also be in danger. During the flood in September 2015, the water inflow peaked at $700 \mathrm{~m}^{3} / \mathrm{s}$ at hourly measurements. During this period, the roads downstream had to be closed and the operators had emptied the magazine for two weeks in advance to manage the inflow of water.

This project is a part of automating the floodgates at Dalsfos. The long-term goal for Skagerak Kraft is to ensure that the TUC flood server is functioning in a satisfactory manner under operating conditions so that the output from the system can be relied upon. This requires storage of input- and output values, receiving correct outputs and being able to check how previous outputs compare to actual results.

\subsection{Previous work}

The development work for the prototype implemented in 2014, was done by faculty members with help from master students at USN, resulting in the Telemark University College (TUC) flood server. The system was implemented as an advisory system to the operators at the power plant, as a first step in an automation project.

The TUC flood server is currently running at Skagerak Energi office in Porsgrunn. This system calculates the optimal floodgate opening for the Dalsfos hydro power plant based on inflow forecast and Model Predictive Control (MPC). How well an MPC controller performs is based on how accurate the model of the system is. The original model for Lake Toke was developed in Thoresen (2011). The model has been described and validated in Master theses at the University college of Southeast Norway (USN). During the flood in September 2015, it was discovered that the model for Lake Toke was insufficient for modeling such extreme conditions. 
The MPC controller for TUC flood server was developed by faculty at current USN (Lie, 2014; Skeie, 2014). The MPC algorithm was implemented in MATLAB (Shampine et al, 2003)., while the TUC Flood Control Converter (TFCC) is the part of the TUC flood server that handles communication between the MPC controller and Skagerak's internal systems, including when to start the MPC controller.

The original TUC flood server stored data in MATLAB matrices as *.mat files, making it difficult to access the data when trying to identify errors for troubleshooting the software. During the summer of 2016, a Data Handler and a Flood management database was developed to replace the storage of data in *.mat files ${ }^{1}$.

\section{System overview}

Figure 1 shows the area around Lake Toke. The part marked in yellow is the catchment for Lake Toke, an area $1156 \mathrm{~km}^{2}$ wide. This is the area where rain- and snowfall (or lack thereof) will affect the water level in Lake Toke.

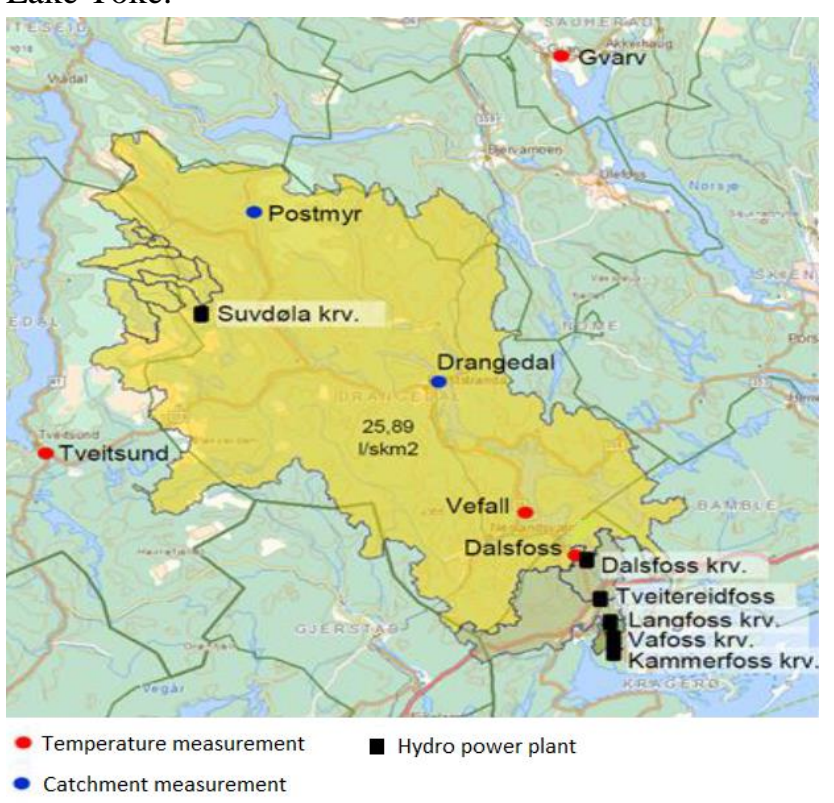

Figure 1. Catchment for Lake Toke. From (Furenes, 2016), legend modified.

Skagerak subscribes to a weather forecast service provided by Storm.no. The hydrologists at Skagerak analyze the catchment data to find a forecast for the water inflow to Lake Toke.

The hydrological data is stored in an internal database called TRADE. A representation of how the TUC flood server interacts with the system at Skagerak is shown in Figure 2. From the TRADE database, the hydrological data is sent along with measurement data from the Dalsfos dam to the TUC flood server. In the TUC flood server, the input data is used to calculate a suggestion for the gate opening, and both the input and output data are stored in an internal database. The output data is sent to a measurement value comparison system, HIDACS. HIDACS will notify the dam operator via text message if any changes should be made to the floodgate opening. HIDACS is connected to sensors at the hydro power plant and sends these values to TRADE (Furenes, 2016).

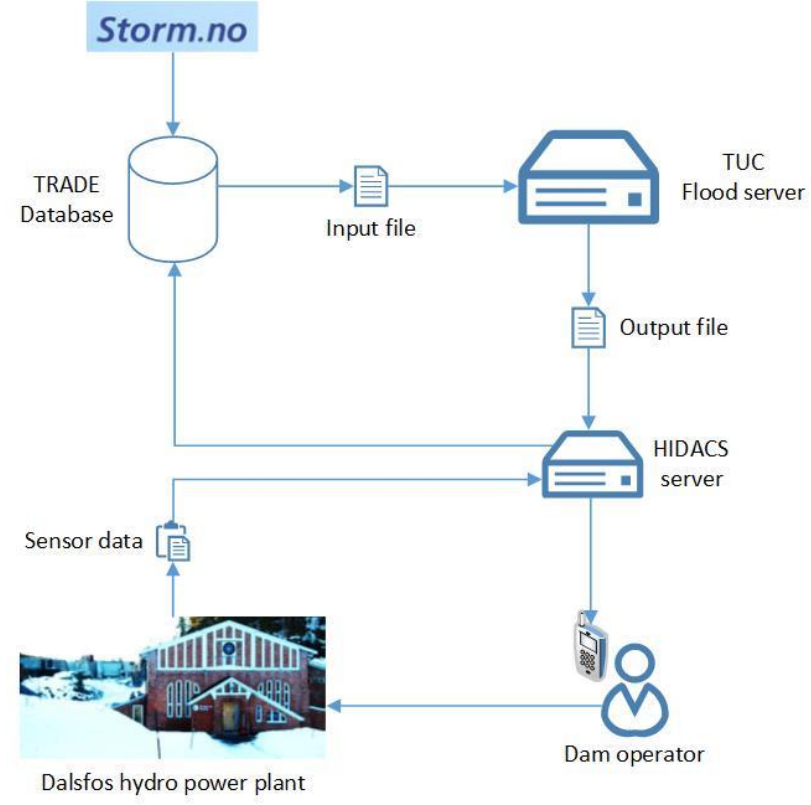

Figure 2. Network representation. From (Furenes, 2016), simplified.

\section{Model tuning}

\subsection{System description}

Experience with the model of Lake Toke and the Dalsfos hydro power plant have shown there is a need for modifying/tuning the model. This section presents the work done on the model. First, a summary of the updated model is presented, followed by a description of which parts were updated and how. Finally, a comparison of the old and the new model are presented.

In Figure 3, a description of the Lake Toke model and its parameters are presented. The model is divided into two parts. The larger part on the left represents the main part of the lake upstream of Merkebekk, and going all the way to Drangedal, etc. The smaller part on the right side of the sketch represents the Dalsfos magazine between Merkebekk and Dalsfos. The parameters presented in the sketch are as follows (beginning from the top of the sketch, left to right):

- $\quad x$ is the height of the water level relative to sea level [m.a.s.l.] ( $\mathrm{x}_{\mathrm{M}}$ - Merkebekk, $\mathrm{x}_{\mathrm{D}}$ - Dalsfos).

${ }^{1}$ The Data Handler and the Flood management database were developed by A. Gjerseth for Skagerak Kraft AS. 
- $\mathrm{h}$ is the height $[\mathrm{m}]$ of the water level above the minimum height $\mathrm{x}_{\mathrm{LRV}}{ }^{\min }\left(\mathrm{h}_{1}-\right.$ Merkebekk, $\mathrm{h}_{2}$ Dalsfos).

- $\dot{\mathrm{V}}_{\mathrm{i}}$ is the inflow of water from the catchment to the lake/magazine $\left[\mathrm{m}^{3} / \mathrm{s}\right]$.

- The $\beta$ parameter determines the distribution of the catchment water inflow amongst the two parts.

- $\mathrm{X}_{\mathrm{HRV}}{ }^{\mathrm{max}}$ is the maximum allowed water level [m.a.s.l.].

- $\dot{\mathrm{V}}_{12}$ is the flow of water $\left[\mathrm{m}^{3} / \mathrm{s}\right]$ from Merkebekk to Dalsfos magazine. This value is assumed to depend on the height difference between Merkebekk and Dalsfos.

- $\quad \dot{\mathrm{V}}_{\mathrm{g}}$ is the water flow through the floodgates at Dalsfos $\left[\mathrm{m}^{3} / \mathrm{s}\right]$. This value is derived from measuring the floodgate opening $[\mathrm{m}]$ and the level at Dalsfos.

- $\dot{\mathrm{V}}_{\mathrm{t}}$ is the water flow through the turbines at Dalsfos $\left[\mathrm{m}^{3} / \mathrm{s}\right]$. This value is derived from measuring the power production of the turbines, $\dot{\mathrm{W}}_{\mathrm{e}}[\mathrm{MWh}]$.

- The $\alpha$ parameter determines the distribution of the surface area of each part, and thus the mass of water in each part.

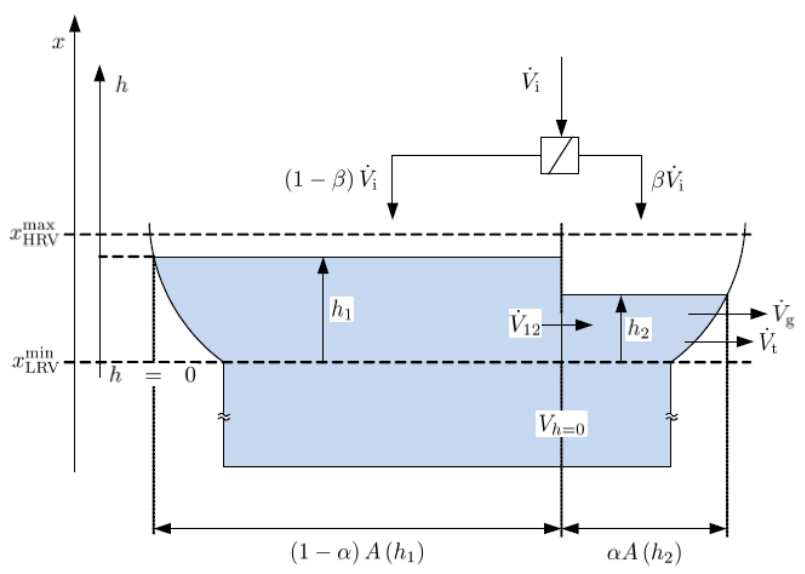

Figure 3. Sketch of Lake Toke (Lie, 2014).

\subsection{New model summary}

The updated model is presented below in Equations 1-9. The parameters, and their values, are given in Table 1.

- $\quad \mathrm{h} 1$ and h2 are the states of the model

- $\mathrm{h}_{\mathrm{g}}$ is the control input (which can be varied at will)

- $\mathrm{V}_{\mathrm{i}}$ is the predicted inflow of water given by the hydrology model (disturbance)

- $\dot{\mathrm{W}}_{\mathrm{e}}$ is the planned power production (disturbance)

- The outputs are: $\mathrm{x}_{\mathrm{M}}, \mathrm{x}_{\mathrm{D}}, \mathrm{V}_{\mathrm{t}}$ and $\dot{\mathrm{V}}_{\mathrm{g}}$

$$
\frac{d h_{1}}{d t}=\frac{1}{(1-\alpha) A\left(h_{1}\right)}\left[(1-\beta) \dot{\mathrm{V}}_{\mathrm{i}}-\dot{V}_{12}\right]
$$

$$
\frac{d h_{2}}{d t}=\frac{1}{\alpha A\left(h_{2}\right)}\left(\beta \dot{\mathrm{V}}_{\mathrm{i}}+\dot{V}_{12}-\dot{V}_{t}-\dot{V}_{g}\right)
$$

Filling curve of Lake Toke:

$$
A(h)=28 \times 10^{6} \cdot 1.1 \cdot h^{\frac{1}{10}}
$$

Inter-compartmental flow (volumetric flow within Lake Toke, from Merkebekk to Dalsfos):

$$
\dot{V}_{12}=k_{1} \cdot \sqrt[4]{h_{1}-h_{2}}+k_{2} \cdot \sqrt{h_{1}-h_{2}}
$$

Volumetric water flow through the floodgate:

$$
\dot{V}_{g}=C_{d} \cdot w \cdot \min \left(h_{g}, h_{2}\right) \sqrt{2 g \cdot \max \left(h_{2}, 0\right)}
$$

The volumetric flow through the turbines is found by choosing the correct root of Equation 6 and inserting the answer into Equation 7:

$$
\begin{aligned}
0=c_{1} x_{q}^{3}+\left(c_{2}\right. & \left.-c_{1} x_{D}\right) x_{q}^{2} \\
& +\left(c_{3}-c_{2} x_{D}+c_{4} \dot{V}_{g}\right) x_{q} \\
& +\dot{W}_{e}-c_{3} x_{D}-c_{4} \dot{V}_{g} x_{D}-c_{5} \\
\dot{V}_{t}= & a \frac{\dot{W}_{e}}{x_{D}-x_{q}}+b
\end{aligned}
$$

Water levels above sea level are given for Dalsfos:

$$
x_{D}=h_{2}+x_{L R V}^{\min }
$$

and for Merkebekk as:

$$
x_{M}=h_{1}+x_{L R V}^{\min }
$$

Table 1. Lake Toke new model parameters.

\begin{tabular}{|c|c|c|l|}
\hline Parameter & Value & Unit & Comment \\
\hline$\alpha$ & 0.01 & - & $\begin{array}{l}\text { Fraction of surface area } \\
\text { in compartment }\end{array}$ \\
\hline$\beta$ & 0.01 & - & $\begin{array}{l}\text { Fraction of inflow to } \\
\text { compartment }\end{array}$ \\
\hline $\mathrm{C}_{\mathrm{d}}$ & 0.7 & - & $\begin{array}{l}\text { Discharge coefficient, } \\
\text { Dalsfos flood gates }\end{array}$ \\
\hline$w_{1}$ & 11.6 & $\mathrm{~m}$ & Width of Dalsfos gate 1 \\
\hline$w_{2}$ & 11.0 & $\mathrm{~m}$ & Width of Dalsfos gate 2 \\
\hline$x_{L R V}^{\min }$ & 55.75 & $\mathrm{~m}$ & $\begin{array}{l}\text { Minimal low regulated } \\
\text { water level }\end{array}$ \\
\hline$x_{H R V}^{\max }$ & 60.35 & $\mathrm{~m}$ & $\begin{array}{l}\text { Maximum high } \\
\text { regulated water level }\end{array}$ \\
\hline $\mathrm{g}$ & 9.81 & $\mathrm{~m} / \mathrm{s}^{2}$ & Acceleration of gravity \\
\hline $\mathrm{k}_{1}$ & 100 & - & Coefficient, Equation 4 \\
\hline $\mathrm{k}_{2}$ & 1 & - & Coefficient, Equation 4 \\
\hline $\mathrm{c}_{1}$ & 0.1315 & - & Coefficient, Equation 6 \\
\hline $\mathrm{c}_{2}$ & -9.524 & - & Coefficient, Equation 6 \\
\hline $\mathrm{c}_{3}$ & 172.34 & - & Coefficient, Equation 6 \\
\hline $\mathrm{c}_{4}$ & $-7.7 \mathrm{e}-3$ & - & Coefficient, Equation 6 \\
\hline $\mathrm{c}_{5}$ & -87.35 & - & Coefficient, Equation 6 \\
\hline $\mathrm{a}$ & 124.69 & - & Coefficient, Equation 7 \\
\hline $\mathrm{b}$ & 3.161 & - & Coefficient, Equation 7 \\
\hline
\end{tabular}




\subsection{Historical data}

The data used for model fitting was provided by Skagerak Kraft AS. The data contains hourly measurements and their derived values, from the period 01/01-2015 to 10/01-2017, totaling 17768 measurement points. The measurements for the water level in Lake Toke and the water inflow to the Dalsfos dam can be seen in Figure 4. The water inflow in the second part of Figure 4 is a derived value supplied by Skagerak Kraft $\mathrm{AS}$, based on internal computations of measurement data. These measured values for water inflow are assumed to be more accurate than the water inflow prediction $\dot{\mathrm{V}}_{\mathrm{i}}$ and used in evaluating the accuracy of the inflow predictions.

When evaluating the data, one can see that the first 4700 values seem to have some measurement errors. It does not make sense that the water level would be almost one meter higher at the point furthest downstream (points 1800-3300), thus creating a negative driving force from Merkebekk to Dalsfos. Then the sensor at Dalsfos seems to fail for an extended period, stuck at the same value. These assumptions can be further verified by looking at the water inflow in the lower half of the Figure 4. There is nothing to indicate the odd behavior that we see in the first 4700 data points. Based on these observations, the first 4800 measurement points of data were excluded from further work.

\subsection{Gate flow parameter updating}

The original floodgate model (Equation 5) is the same as the updated one, but the discharge coefficient $\mathrm{Cd}$ was 1.0 and is now updated to 0.7 . This is simply an update based on information from Norwegian Water Resources and Energy Directorate (NVE) supplied by Skagerak Kraft AS (NVE, 2017).

\subsection{Inter-compartmental flow model reworking}

The inter-compartmental flow for this model is the amount of water flowing from measuring point Merkebekk to Dalsfos based on the water height difference between these two points. The original equation (shown in Equation 10) needed to be reworked based on historical data.

$$
\dot{V}_{12}=K_{12}\left(h_{1}-h_{2}\right) \sqrt{h_{1}-h_{2}}
$$

Similar as to in the old model, it was assumed that the inter-compartmental volumetric flow rate is driven by the level difference between Merkebekk and Dalsfos. The available data was plotted as seen in Figure 5. In this description, it was assumed that the lower compartment (Dalsfos magazine) was at steady state so that the inter-compartmental flow rate equals the sum of the flow through the turbines and the floodgates. The height difference in water level values are from measurements made at the same time as the water flow.

Amongst many possible model structures, the structure proposed in Eq. 4 was used and fitted to the experimental data.

The "measured output" (in this case, the intercompartmental water flow) is described as seen in Equation 4 . The polynomial coefficients $\mathrm{k}_{1}$ and $\mathrm{k}_{2}$ were found by using the Least Squares method (Van Loan, 2000; Christensen and Christensen 2004).

Equation 4 was restructured as seen in Equation 11 where the right hand matrix is referred to as matrix $\Phi$ while the right hand parameter vector is referred to as
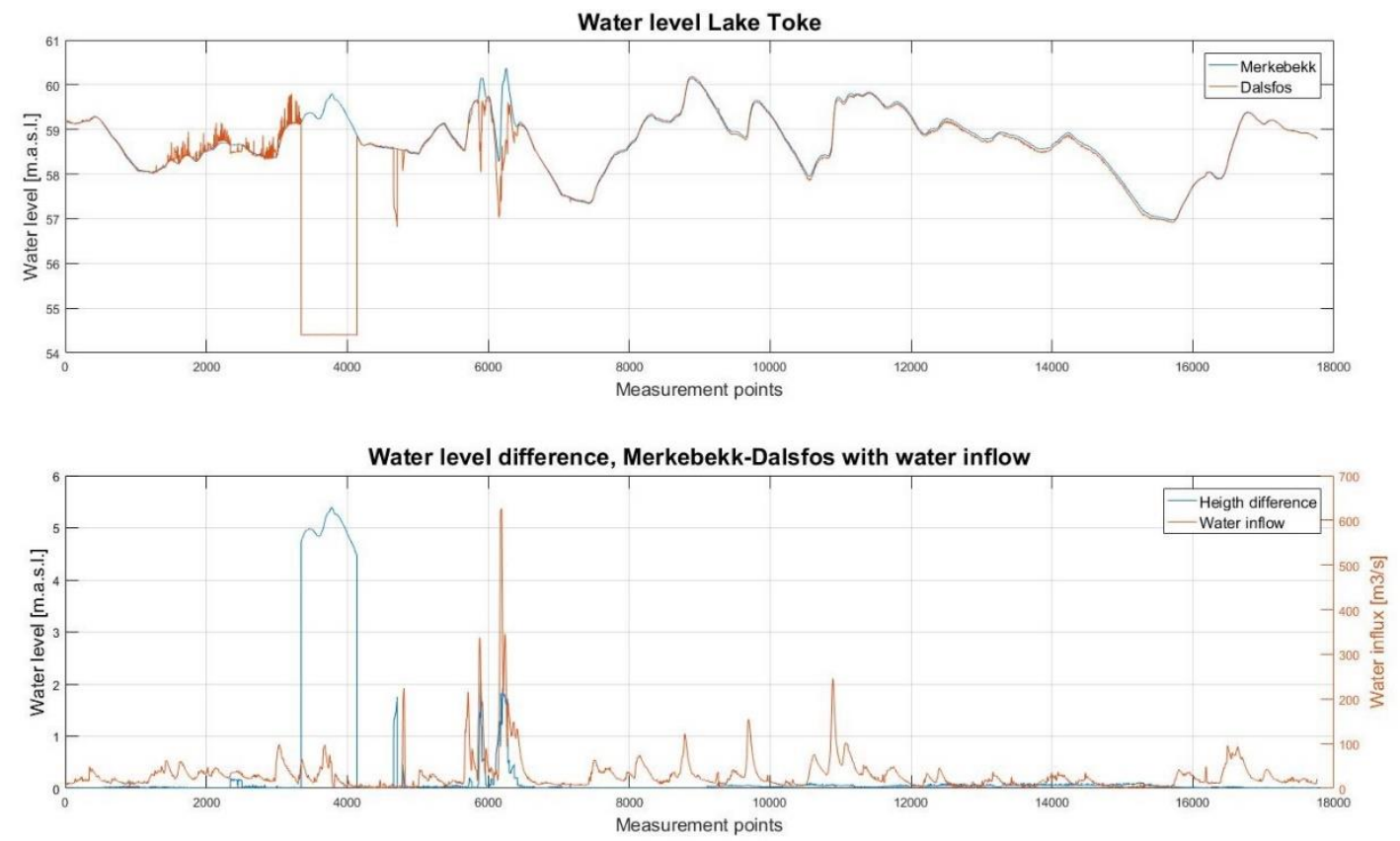

Figure 4. Water level in Lake Toke, 2 measuring points and the difference between them and the measured water inflow to Lake Toke. 


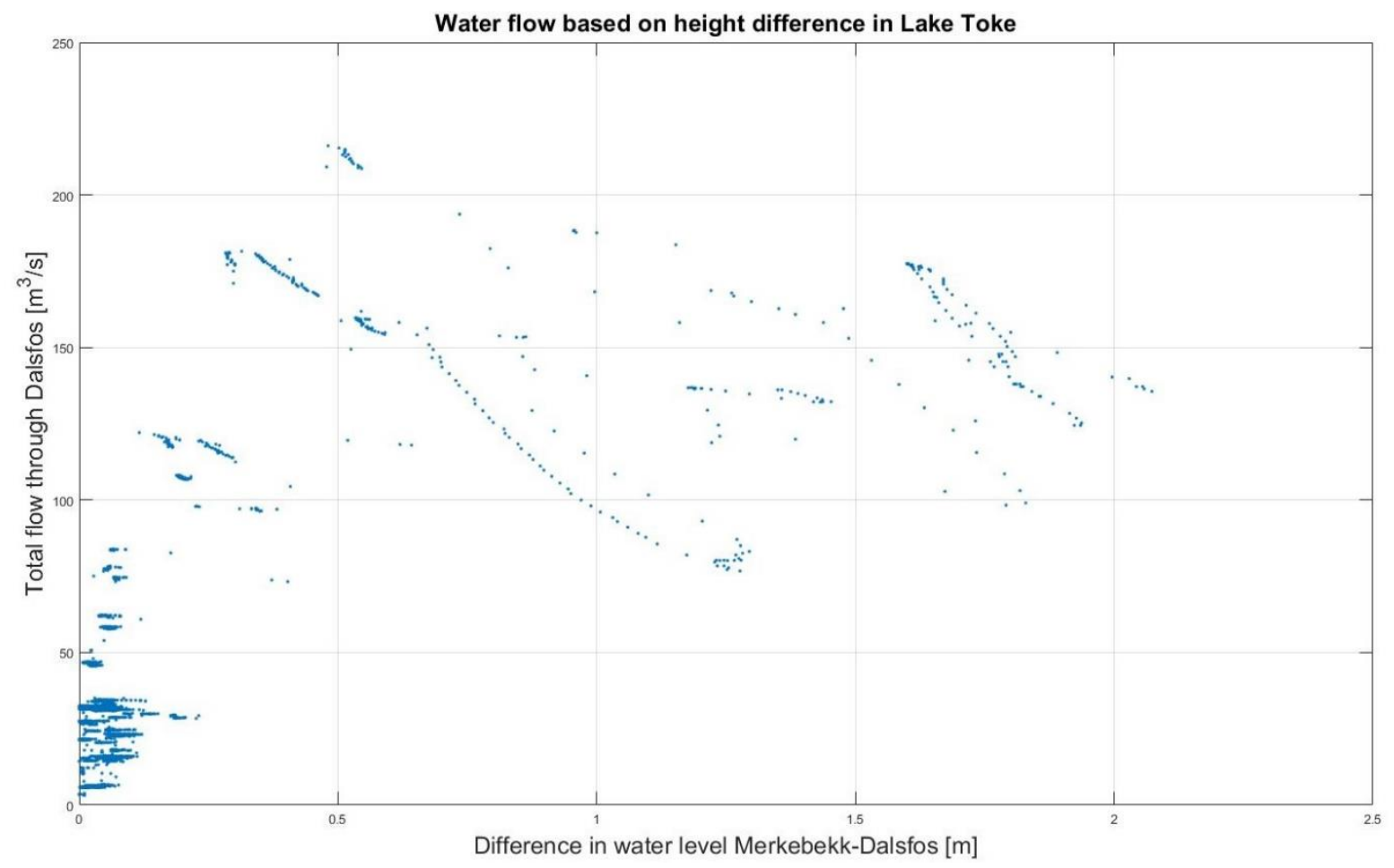

Figure 5. Total water flow through Dalsfos Dam vs. level difference Merkebekk-Dalsfos.

vector $\theta$ resulting in Equation 12. Here, $y$ and $\Phi$ are known, $\theta$ is the unknown.

$$
\begin{gathered}
{\left[\begin{array}{c}
y_{1} \\
y_{2} \\
\vdots \\
y_{N}
\end{array}\right]=\left[\begin{array}{cc}
\sqrt[4]{x_{1}} & \sqrt{x_{1}} \\
\sqrt[4]{x_{2}} & \sqrt{x_{2}} \\
\vdots & \vdots \\
\sqrt[4]{x_{N}} & \sqrt{x_{N}}
\end{array}\right] \cdot\left[\begin{array}{l}
k_{1} \\
k_{2}
\end{array}\right]} \\
y=\Phi \cdot \theta
\end{gathered}
$$

There is available a function in MATLAB called polyfit what will solve Equation 4, but there is no option to edit or weigh the factors. So this function cannot be used since we want the function to go through $(0,0)$ in the plane. This is to ensure that when there is no level difference between the levels at Merkebekk and at Dalsfos, there is no flow of water between those locations either. To achieve this, we have to ensure that any constant term is equal to zero. Below is MATLAB code (Higham and Higham, 2005) used for finding the polynomial coefficients.

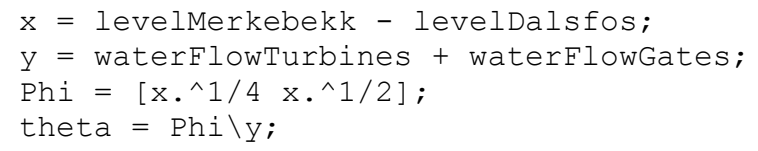

This method of determining the polynomial coefficients was repeated with different orders of the polynomials in $\sqrt[4]{x}$ within matrix $\Phi$ to have polynomials from first to fourth order, all the time with constant term forced to zero to ensure the models goes through the origin. Equation 13 shows the fourth order equation, a simplification of the fractions is shown in equation 14 .
To get the other orders of the polynomial:

- $\quad$ Third order, $\mathrm{k}_{4}=0$

- Second order, $\mathrm{k}_{3}$ and $\mathrm{k}_{4}=0$ (Eq. 4)

- First order, $\mathrm{k}_{2}, \mathrm{k}_{3}$ and $\mathrm{k}_{4}=0$

For compactness, the water level difference is defined as $d_{h}=h_{1}-h_{2}$ here.

$$
\begin{aligned}
\dot{V}_{12}=k_{1} \cdot \sqrt[4]{d_{h}} & +k_{2} \cdot \sqrt[4]{d_{h}{ }^{2}}+k_{3} \cdot \sqrt[4]{d_{h}{ }^{3}} \\
& +k_{4} \cdot \sqrt[4]{d_{h}{ }^{4}} \\
\dot{V}_{12}=k_{1} \cdot \sqrt[4]{d_{h}} & +k_{2} \cdot \sqrt{d_{h}}+k_{3} \cdot \sqrt[4]{d_{h}{ }^{3}} \\
& +k_{4} \cdot d_{h}
\end{aligned}
$$

The resulting models were plotted in Figure 6 against the measurement data to determine how well they fit the target data. In this figure, we see that the first order polynomial (green) falls outside of the data. The fourth order polynomial (orange) results in a parabola which is counter intuitive; the flow of water should be strictly increasing with the level difference. Finally, we see that the second and third order polynomials are nearly identical and give a decent fit to the data. Since the third order polynomial offers no extra information, the second order polynomial was chosen.

\subsection{ODE parameter tuning}

The $\alpha$ and $\beta$ parameters in Equations 1 and 2 were originally set to 0.05 and 0.02 . This was an experiencebased estimate done when the model was first 


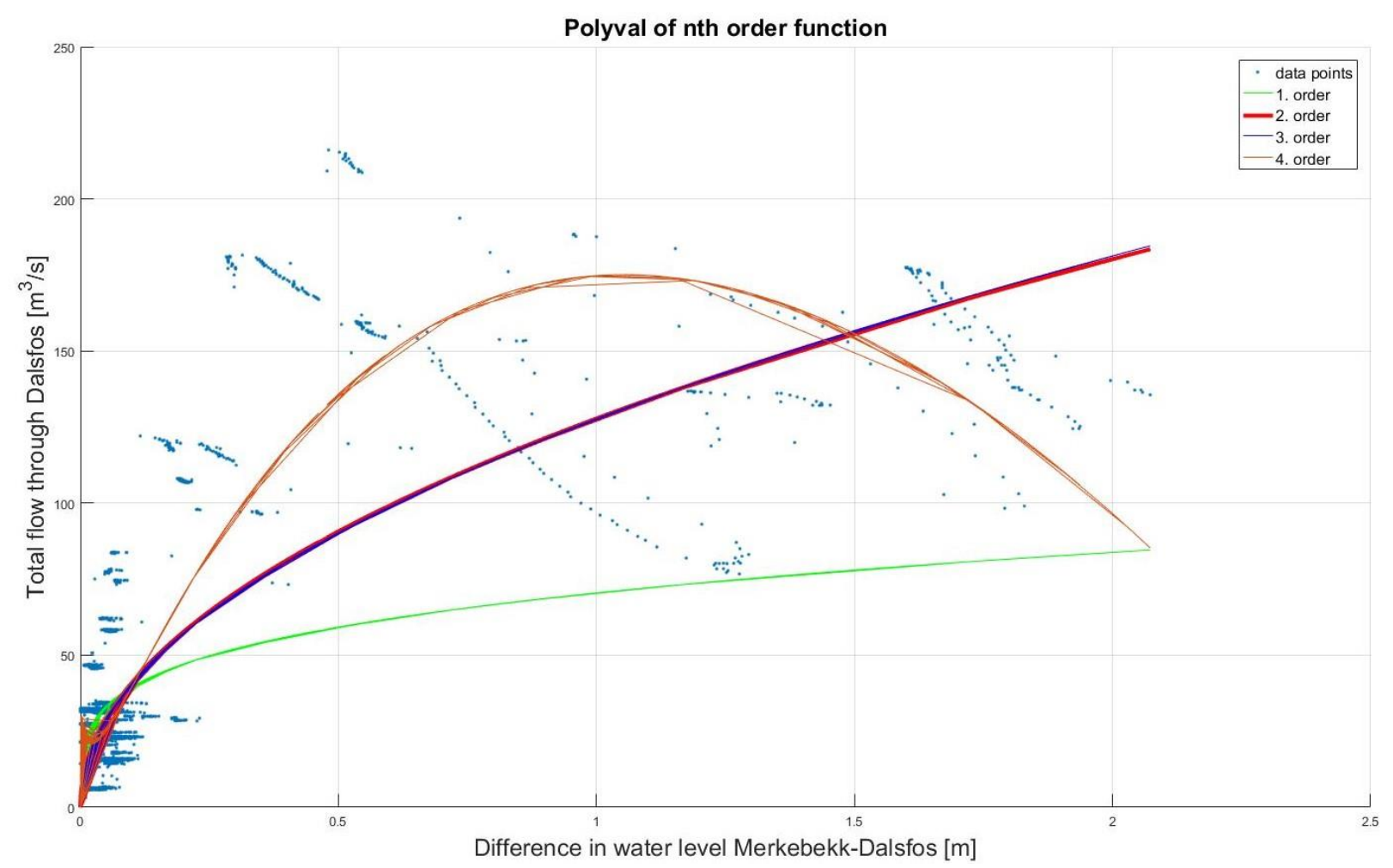

Figure 6. Polynomial evaluation, different order of fitted function.

developed. To estimate new values, the built-in MATLAB function lsqnonlin was used. "Isqnonlin" is a nonlinear least-squares solver that solves nonlinear least-squares curve fitting problems (Mathworks, 2017).

A MATLAB script was developed to tune the $\alpha$ - and $\beta$ parameters. The historical measurement data provided by Skagerak was used as the target data. lsqnonlin was supplied with the updated model of Lake Toke and the option to vary the parameters. Isqnonlin tries out different values for the parameters, constantly trying to minimize the difference between the output of the model and the target data.
Once suitable values for the $\alpha$ and $\beta$ parameters were obtained, the tuning of parameters $\mathrm{k}_{1}$ and $\mathrm{k}_{2}$ (as described in section 3.5, Equations 11-13) was redone with the updated $\alpha$ and $\beta$ parameters. The values for $\mathrm{k}_{1}$ and $\mathrm{k}_{2}$ presented in Table 1 are those obtained from this second tuning.

\subsection{Model verification}

To test the model updates, a simulation (described in section 4.2) was run to compare new and the old model as seen in Figure 7. The data chosen was from early august 2015 and thirty days ahead into the beginning of

Simulation of water levels (new model)

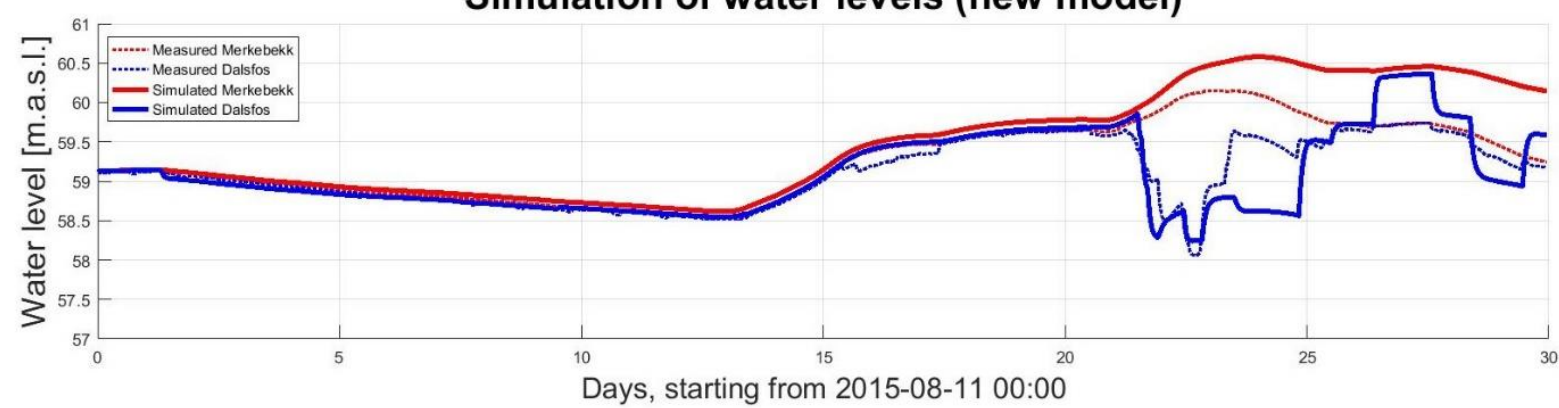

Simulation of water levels (old model)

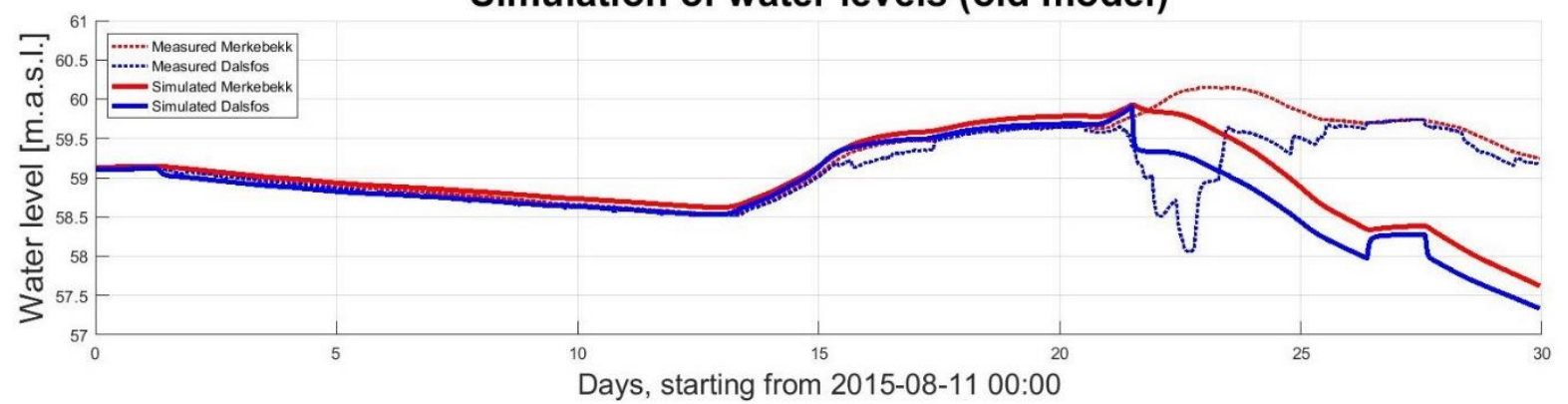

Figure 7. Model verification simulation. 
the large flood in September 2015. The blue lines show the water level in Dalsfos and the red lines show the water level in Merkebekk. The dotted lines are measured data while the solid lines are the simulated values. How the plot in Figure 7 was created is described in section 4.2. The results of the plot are discussed in section 5.2.

\section{TUC Flood Server}

\subsection{Server structure}

The TUC flood server consists of three subsystems:

- Data Handler, a C\# application

- Flood management, an SQL database

- $\quad$ MPC controller, a MATLAB application

The Data Handler runs continuously, monitoring the input folder for new files and starts the MPC controller at chosen intervals. When the Data handler detects a new file, it reads the input values in the file and stores all the input values in the Flood management database.

When the MPC controller is started, it queries the database for the newest input values and imports these. This data is used by the controller for simulating the system and calculating future gate openings. The output values are stored in both an output file and in the Flood management database. How the subsystems interact is shown in Figure 8.

\subsection{Simulating the model by fetching data from the database}

By using the model functions developed for the MPC controller and gathering data from the Flood management database, a simulator was developed. The main use of the simulator is for comparing the possible performance of the MPC algorithm compared to historical data.

The user chooses a start date and for how many days the simulation should run. Assuming that the needed data is available, the Simulator will use the values to initiate the model. The model is supplied with the initial values of the levels at Merkebekk and Dalsfos, the current and future position of the floodgates and the current and future power production from the turbines. Under normal operations, the model would be supplied with predictions for the water inflow and a production plan for the turbines. Since historical data is available, the model is supplied with measurement data of the water inflow and of the turbine power production for the simulation period.

The data stored in the database is structured around which (input- or output) file it belongs too and the data type. So when querying the database, it is possible retrieve one or several values from a given file or data type. MATLAB has a built-in toolbox named ODBC which has been used to handle communication between the MPC controller and the database. The MATLAB functions developed to integrate the MPC controller with the database were designed to be as general as possible. This was done to ensure that the functions could be re-used for simulations and for specific queries by the user.

\section{Discussion}

\subsection{Inter-compartmental flow model assumptions and available data}

The model for the inter-compartmental flow (section 3.5) is based on the assumption that the flow of water from Merkebekk to Dalsfos is the same as the computed flow through the floodgates and turbines at Dalsfos. There are some issues with this assumption that needs to be considered.

First, it was observed in Figure 4 that some of the oldest measurement data was unreliable. It is possible that some of the more recent data also could be an error source.

The data plotted in Figure 5 is quite scattered, making it difficult to find a function to fit the data. One possible

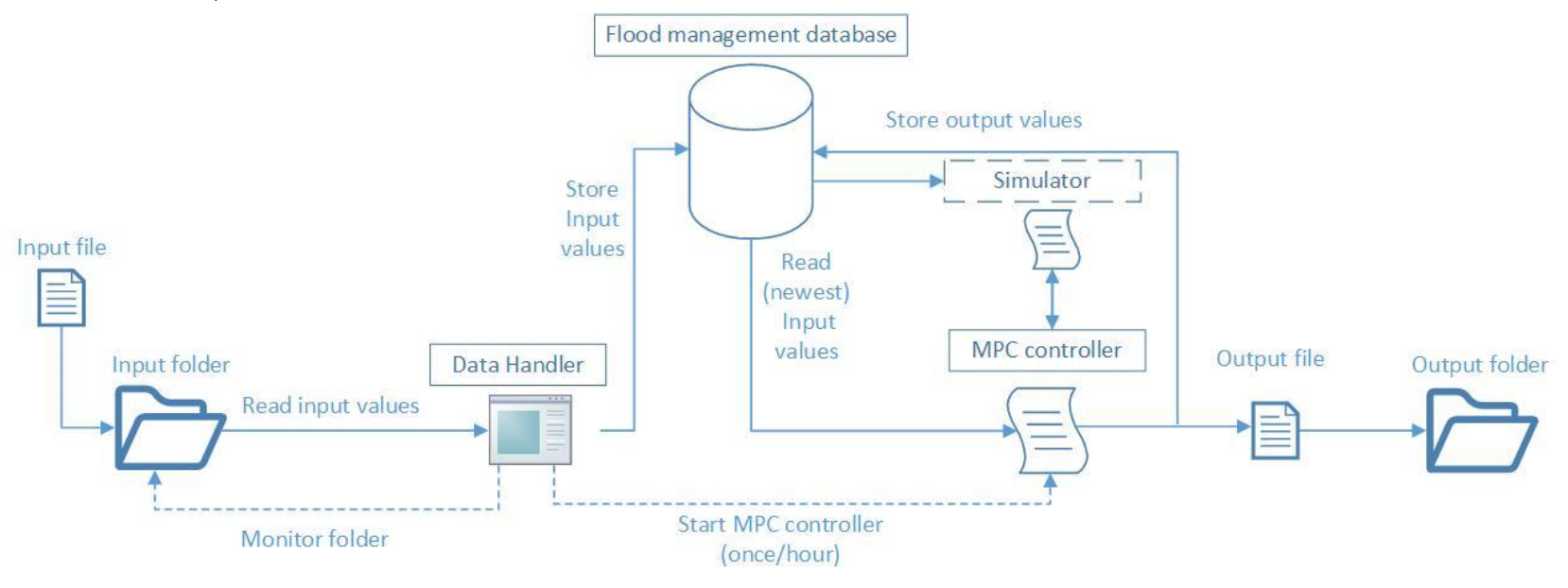

Figure 8. TUC Flood server subsystems and interactions. 
source of error is that there may be accumulation of water in the lower volume, i.e., in the dam in front of the flood gates - we have neglected this dynamics by assuming that the flow into this dam equals the flow out of the dam. Another source of error is that the models for computing flow through the turbines and flow through the floodgates may be inaccurate.

Lastly, it is possible that during a flood, water "leaks" into the ground - at least if the flood comes after a dry period, and until the flooded area becomes saturated with water.

To further improve on the inter-compartmental flow model, some advanced analysis methods and strategies would have to be explored.

\subsection{Model verification simulation}

In Figure 7, we can observe how the new and the old models perform in simulation when compared to historical data. model:

The figure reflects some of the changes made to the

- Both models handle the simulation for the first 21 days well. This is as expected, as the old model functioned well under regular condition and there have not been made major changes in that regard.

- The new model shows improvement over the old one once the flood starts to build up. There is still deviation from the measured data, but the general trend is followed.

Some of the deviations in Figure 7 show up when the floodgates are opened, and it is thus reasonable to attribute them to inaccuracies of the floodgate model. On day 26-27, both models show a sudden jump of almost one meter of the level in Dalsfos in a very short period of time and then again an equally abrupt drop about one day later. These sudden jumps coincide with the sudden closing and opening of the flood gates.

\section{Conclusions}

The new model shows improvement compared to the old one; this improvement is particularly seen during floods, which is when the optimization of the floodgates actually is important. With the new database for handling information, the foundation is laid for further improving the model when more data becomes available.

The model still has room for improvement, in particular the models for the inter-compartment flow and the floodgate flow should be examined further.

Data storage and use has been made simpler now with the implementation of a database to store input- and output values. This inclusion has made troubleshooting and further work simpler.
There remains some work in regards to the user interface of the Data Handler and error handling for the MPC controller.

Future work:

- Further tuning of model, with particular emphasis of floodgate models.

- Improve efficiency of model.

- Data Handler: Include UI to display status messages directly to the user.

- MPC controller: Error- handling and reporting to the database should be implemented.

\section{References}

B. Furenes. MPC PA FLOMLUKEHÅNDTERING I KRAGERØVASSDRAGET. Presentation. Porsgrunn, Norway, 2016.

O. Christensen and K.L. Christensen (2004). Approximation Theory. From Taylor Polynomials to Wavelets. Birkhäuser, Boston.

A.Z. Gjerseth. Systembeskrivelse. Tech. rep. Telemark University College, Porsgrunn, Norway, Aug. 2016.

D.J. Higham and N.J. Higham (2005). MATLAB Guide, third edition. SIAM, Philadelphia, USA. 978-1-61197-465-2.

B. Lie. Final report: KONTRAKT NR INAN-140122 Optimal Control of Dalsfos Flood Gates - control algorithm. Tech. rep. Telemark University College, Porsgrunn, Norway, July 2014.

Mathworks. 1sqnonlin. Article on the Internet. 20 Mar 2017. url:https://se.mathworks.com/help/optim/ug/lsqnonlin.htm.

C. Van Loan (2000). Introduction to Scientific Computing. A Matrix-Vector Approach Using MATLAB, Second Edition. Prentice-Hall, Upper Saddle River, New Jersey. ISBN-13: 978-0139491573.

L.F. Shampine, I. Gladwell, S. Thompson (2003). Solving ODEs with MATLAB. Cambridge University Press, Cambridge, UK.

N-O. Skeie. KONTRAKT NR INAN-140122 Optimal styring av Dalsfos Flomporter - Grensesnitt mellom GS2 Filformat og Flomprognosesystem med MPC fra Høgskolen i Telemark (HiT). Tech. rep. Telemark University College, Porsgrunn, Norway, June 2014.

H. M. Thoresen, "Control and optimization of Kragerøvassdraget," Telemark University College, Porsgrunn, 2011.

NVE (Norges vassdrags- og energidirektorat). Retningslinjer for floml $\varnothing$ p. Publication on the Internet. 17 Jan 2017. url: http://publikasjoner.nve.no/retningslinjer/2005/retningslinj er2005_02.pdf. 